\title{
An Uncertain Wage Contract Model with Adverse Selection and Moral Hazard
}

\author{
Xiulan Wang, ${ }^{1,2}$ Yanfei Lan, ${ }^{1}$ and Jiao Wang ${ }^{1}$ \\ ${ }^{1}$ Institute of Systems Engineering, Tianjin University, Tianjin 300072, China \\ ${ }^{2}$ College of Science, Tianjin Polytechnic University, Tianjin 300387, China \\ Correspondence should be addressed to Yanfei Lan; yanfei-lan@163.com
}

Received 8 October 2013; Revised 24 February 2014; Accepted 28 February 2014; Published 27 March 2014

Academic Editor: Shan Zhao

Copyright (C) 2014 Xiulan Wang et al. This is an open access article distributed under the Creative Commons Attribution License, which permits unrestricted use, distribution, and reproduction in any medium, provided the original work is properly cited.

This paper considers a wage contract design problem faced by an employer (he) who employs an employee (she) to work for him in labor market. Since the employee's ability that affects the productivity is her private information and cannot be observed by the employer, it can be characterized as an uncertain variable. Moreover, the employee's effort is unobservable to the employer, and the employee can select her effort level to maximize her utility. Thus, an uncertain wage contract model with adverse selection and moral hazard is established to maximize the employer's expected profit. And the model analysis mainly focuses on the equivalent form of the proposed wage contract model and the optimal solution to this form. The optimal solution indicates that both the employee's effort level and the wage increase with the employee's ability. Lastly, a numerical example is given to illustrate the effectiveness of the proposed model.

\section{Introduction}

Wage mechanism design problem is important for the employer, which is related to the development of the firm the employer owns. An efficient wage payment mechanism can incentivize the employee to work hard and bring greater profit for the employer. This paper investigates the employment relationship between the employer and his employee, in which the employee has private information on her ability that is closely related to the employer's productivity. Furthermore, the effort of the employee which also influences the employer's productivity is unobservable to the employer. Thus, the wage mechanism design problem is studied under this environment.

In real life, many problems can be analyzed by principalagent theory. In the initial research of the principal-agent problems, adverse selection and moral hazard are often separable. Myerson [1] established a principal-agent model with adverse selection only, and Grossman and Hart [2] investigated the principal-agent problem under moral hazard. Later, Page [3] studied the optimal contract mechanism for principal-agent problem with adverse selection and moral hazard. In recent years, principal-agent theory has been applied to other research fields. For instance, Özer and Raz [4] considered supply chain sourcing under asymmetric information, and Lan et al. [5] studied multifirm regulation problem applying principal-agent theory.

Most literature on wage contract design problem described the involving of uncertain information as random variable. For instance, Greenwald [6] studied adverse selection problem in labor market; Chen [7] presented wage contract for salespeople under adverse selection and moral hazard; these wage contracts were designed under random environment. However, in practice, due to the paucity of the historical data about the private information which cannot be exactly described in advance, the frequency cannot be known for the participator. Therefore, probability theory is no longer appropriate to characterize this kind of private information; this is because the probability distribution of the private information cannot be estimated from the frequency for the lack of it. In addition, Liu [8] alleged that probability theory may give rise to counterintuitive results in this situation. As a result, a new approach, based on the experts' subjective judgment, called uncertainty theory [9], was proposed. Since then uncertain theory has become a powerful mathematical tool to handle various 
issues under incomplete information, for instance, uncertain control [10], uncertain differential equation [11], uncertain programming [12-16], uncertain principal-agent [17-19], uncertain random programming [20], and so forth. For more details on uncertainty theory, the interested reader can refer to Liu [20, 21]. Applying uncertainty theory, Wang et al. [22] and $\mathrm{Mu}$ et al. [23] provided uncertain wage contract models with adverse selection only. However, the uncertain wage contract design problem with adverse selection and moral hazard has not been together examined in the existing literature.

This paper investigates an uncertain wage contract design problem with adverse selection and moral hazard in labor market. The ability of the employee is her private information, which is unknown to the employer, and he can only take a personal assessment. Thus, considering this unknown parameter as an uncertain variable is more reasonable rather than a random variable. Moreover, the employee's effort level that she expends on her work is unobservable, and she can choose an appropriate effort level to maximize her utility. Then an uncertain wage contract model is established to maximize the expected profit of the employer. The crisp equivalent model is presented and the optimal solution is obtained. The results show that if the ability of the employee is higher, the effort level that the employee is willing to pay is higher and the wage paid by the employer is higher; that is, with the increase of the employee's ability, both the employee's effort level and her wage increase.

The remainder of this paper is arranged as follows. Section 2 reviews some basic concepts about uncertain variables. Section 3 presents the uncertain wage contract model in the presence of adverse selection and moral hazard. Section 4 provides the equivalent form of the model and obtains the optimal solution of the equivalent model by variational method. Section 5 presents a numerical example to testify the effectiveness of the proposed model. Section 6 summarizes the main conclusions of this paper.

\section{Preliminaries}

Uncertain theory was founded by Liu [9] and has become a branch of axiomatic mathematics. Nowadays, more and more researchers pay attention to uncertain theory. Let $\Gamma$ be a nonempty set, and let $\mathscr{L}$ be a $\sigma$-algebra of $\Gamma$. Each element $\Lambda$ in $\mathscr{L}$ is called an event. The triplet $(\Gamma, \mathscr{L}, \mathscr{M})$ is called an uncertain space. Uncertain measure is a set function defined on $\Gamma$ and satisfies the following four axioms.

Axiom 1 (normality axiom). $\mathscr{M}(\Gamma)=1$ for the universal set $\Gamma$.

Axiom 2 (duality axiom). $\mathscr{M}(\Lambda)+\mathscr{M}\left(\Lambda^{c}\right)=1$ for any event $\Lambda$.

Axiom 3 (subadditivity axiom). For every countable sequence of events $\Lambda_{1}, \Lambda_{2}, \ldots$, there exists

$$
\mathscr{M}\left\{\bigcup_{i=1}^{\infty} \Lambda_{i}\right\} \leq \sum_{i=1}^{\infty} \mathscr{M}\left\{\Lambda_{i}\right\} \text {. }
$$

Axiom 4 (product axiom [24]). Let $\left(\Gamma_{k}, \mathscr{L}_{k}, \mathscr{M}_{k}\right)$ be uncertainty spaces for $k=1,2, \ldots, n$. Then the product uncertain measure $\mathscr{M}$ defined on the product $\sigma$-algebra $\mathscr{L}_{1} \times \mathscr{L}_{2} \times \cdots \times$ $\mathscr{L}_{n}$ satisfies

$$
\mathscr{M}\left\{\prod_{k=1}^{n} \Lambda_{k}\right\}=\min _{1 \leq k \leq n} \mathscr{M}\left\{\Lambda_{k}\right\} .
$$

Definition 1 (see [9]). An uncertain variable $\xi$ is a measurable function from an uncertain space $(\Gamma, \mathscr{L}, \mathscr{M})$ to the set of real numbers.

Definition 2 (see [9]). The uncertainty distribution $\Phi$ of an uncertain variable $\xi$ is defined by $\Phi(x)=\mathscr{M}\{\xi \leq x\}$ for any real number $x$.

Definition 3 (see [9]). If $f$ is a measurable function and $\xi_{1}, \xi_{2}, \ldots, \xi_{n}$ are uncertain variables on uncertain space $(\Gamma, \mathscr{L}, \mathscr{M})$, then $\xi=f\left(\xi_{1}, \xi_{2}, \ldots, \xi_{n}\right)$ is an uncertain variable defined as $\xi(\theta)=f\left(\xi_{1}(\theta), \xi_{2}(\theta), \ldots, \xi_{n}(\theta)\right)$ for any $\theta \in \Gamma$.

Definition 4 (see [9]). The expected value of uncertain variable $\xi$ is defined as follows:

$$
E[\xi]=\int_{0}^{+\infty} \mathscr{M}\{\xi \geq r\} d r-\int_{-\infty}^{0} \mathscr{M}\{\xi \leq r\} d r
$$

provided that at least one of the two integrals is finite.

Lemma 5 (see [25]). Let $\xi$ be an uncertain variable with uncertain distribution $\Phi(x)$ and $g$ a monotone real value function; then the expected value of $g(\xi)$ is

$$
E[g(\xi)]=\int_{-\infty}^{+\infty} g(x) d \Phi(x) .
$$

\section{An Uncertain Wage Contract Model}

In this section, we present an uncertain wage contract model in which adverse selection and moral hazard are considered simultaneously. In labor market, the employer is treated as a principal while the employee is treated as an agent, and both are risk neutral. The employee has private information about her ability, which is unknown to employer and can be characterized as an uncertain variable $\xi$. The employee's effort level $e$ is unobservable to the employer, and the employer can infer from the ex post productivity. For simplicity, assume that one employer employs one employee, and let $q=k_{1} e+$ $k_{2} \xi$ be the productivity of the employee, where $k_{1}$ and $k_{2}$ are positive parameters.

Before the contract is signed, the employee knows her ability $x$, but the employer is just aware of the distribution $\Phi(x)$ of $\xi$ on $[\underline{x}, \bar{x}]$, where $\underline{x}>0$. Denote $\phi(x)=\Phi^{\prime}(x)$ and assume that $(d / d x)((1-\Phi(x)) / \phi(x))<0$, which is a common condition in private information agency literature. If the employee accepts the contract, she will choose an optimal effort level to maximize her net income $U(w, e)=$ $w-C(e)$, where $w$ is the wage that the employer pays and $C(e)=(1 / 2) c e^{2}$ is the cost of her effort which is unknown to the employer $[26,27] ; c>0$ is a known parameter. The sequence of the game is summarized as follows. 
(1) Nature chooses a "type" $x$ for the employee.

(2) The employer provides a wage contract menu which is related to the employee's type. If the employee refuses the contract, the game is ended; otherwise, enter into (3).

(3) The employee reports her type $x$ then chooses an appropriate effort level to start production.

(4) The productivity is realized, the employer pays the corresponding wage to the employee, and the game is ended.

The employer is desired to design a wage contract menu $w(q)=a(x)+b(x) q$ to maximize his expected profit, where $a(x)$ is referred to as the fixed wage, $b(x) q$ is the performance pay, $b(x)$ is called bonus coefficient, and $0 \leq b(x)<1$. This wage payment is often used in reality and can motivate the employee to work hard. The cost of production is assumed to be zero, and the price of the productivity is normalized to one; the employer's only cost is the wage paid; thus, the profit of the employer

$$
V(q)=q-w(q)=k_{1} e+k_{2} x-a(x)-b(x)\left(k_{1} e+k_{2} x\right) .
$$

The objective of the employer is to maximize his expected profit by designing a wage mechanism $w(\cdot)$, subject to the employee's optimal behavior. From the Revelation Principle [28], the employer's choice of a wage contract $w(\cdot)$ is equivalent to the choice of a suitable pair of functions $(a(\cdot), b(\cdot))$.

The optimal effort of the employee satisfies

$$
e^{*}(x) \in \arg \max _{e(\cdot)}\left(a(x)+b(x)\left(k_{1} e(x)+k_{2} x\right)-\frac{1}{2} c e^{2}(x)\right),
$$

which indicates that the employee can determine the optimal effort by maximizing her utility.

The incentive compatible constraint of the employee should satisfy

$$
\begin{array}{r}
a(x)+b(x)\left(k_{1} e(x)+k_{2} x\right)-\frac{1}{2} c e^{2}(x) \\
\geq a(y)+b(y)\left(k_{1} e(y)+k_{2} x\right)-\frac{1}{2} c e^{2}(y), \\
\forall x, y \in[\underline{x}, \bar{x}],
\end{array}
$$

which means the employee with ability $x$ would choose $(a(x), b(x))$ to maximize her utility.

The participation constraint of the employee is

$$
a(x)+b(x)\left(k_{1} e(x)+k_{2} x\right)-\frac{1}{2} c e^{2}(x) \geq u_{0}
$$

where $u_{0}\left(u_{0}>0\right)$ is the employee's reservation utility.
As a consequence, the uncertain wage contract model can be formulated as

$$
\begin{array}{ll}
\max _{e(\cdot), a(\cdot), b(\cdot)} & E\left[k_{1} e(\xi)+k_{2} \xi-a(\xi)-b(\xi)\left(k_{1} e(\xi)+k_{2} \xi\right)\right] \\
\text { subject to: } \quad e^{*}(x) \in \arg \max _{e(\cdot)}\left(a(x)+b(x)\left(k_{1} e(x)+k_{2} x\right)\right. & \left.\quad-\frac{1}{2} c e^{2}(x)\right), \quad \forall x \in[\underline{x}, \bar{x}] \\
& a(x)+b(x)\left(k_{1} e(x)+k_{2} x\right) \\
& -\frac{1}{2} c(e(x))^{2} \geq a(y)+b(y)\left(k_{1} e(y)+k_{2} x\right) \\
& -\frac{1}{2} c(e(y))^{2}, \quad \forall x, y \in[\underline{x}, \bar{x}] \\
& a(x)+b(x)\left(k_{1} e(x)+k_{2} x\right) \\
& -\frac{1}{2} c(e(x))^{2} \geq u_{0}, \quad \forall x \in[\underline{x}, \bar{x}] .
\end{array}
$$

\section{Model Analysis}

4.1. Equivalent Model for Uncertain Wage Contract Problem. In this subsection, we analyze Model (9) and present its equivalent form.

Proposition 6. The optimal effort of the employee satisfies

$$
e^{*}(x)=\frac{k_{1}}{c} b(x) \text {. }
$$

Proof. Since the second-order condition

$$
\frac{\partial^{2} U(w, e)}{\partial e^{2}}=-c<0
$$

it follows from the first-order condition $\partial U(w, e) / \partial e=0$ that the optimal effort of the employee satisfies

$$
e^{*}(x)=\frac{k_{1}}{c} b(x) \text {. }
$$

The proof is complete.

The result of Proposition 6 indicates that the effort level of the employee is positively related to the bonus coefficient of the wage; that is, if the bonus coefficient is higher, the more effort the employee is willing to pay. 
Replace $e(x)$ in Model (9) by $e^{*}(x)$; Model (9) can be rewritten as

$$
\begin{array}{cc}
\max _{a(\cdot), b(\cdot)} \quad E\left[\frac{k_{1}^{2}}{c} b(\xi)+k_{2} \xi-a(\xi)-\frac{k_{1}^{2}}{c} b^{2}(\xi)-k_{2} \xi b(\xi)\right] \\
\text { subject to: } \quad a(x)+\frac{k_{1}^{2}}{2 c} b^{2}(x)+k_{2} x b(x) \\
\geq a(y)+\frac{k_{1}^{2}}{2 c} b^{2}(y)+k_{2} x b(y), \\
\forall x, y \in[\underline{x}, \bar{x}] \\
a(x)+\frac{k_{1}^{2}}{2 c} b^{2}(x)+k_{2} x b(x) \geq u_{0}, \\
\forall x \in[\underline{x}, \bar{x}] .
\end{array}
$$

In the following, the equivalent forms of the constraint conditions and the objective function of Model (13) are deduced.

Proposition 7. The incentive compatibility constraint in Model (13) is equivalent to

$$
\begin{gathered}
a^{\prime}(x)+\left(k_{2} x+\frac{k_{1}^{2}}{c} b(x)\right) b^{\prime}(x)=0, \\
b^{\prime}(x)>0 .
\end{gathered}
$$

Proof. Let $N(x, y)=a(y)+\left(k_{1}^{2} / 2 c\right) b^{2}(y)+k_{2} x b(y)$, which is the income of the employee with the ability $x$ but choose the contract $(a(y), b(y))$ rather than $(a(x), b(x))$, where $x, y \in$ $[x, \bar{x}], x \neq y$. For any given $x$, the incentive compatibility constraint in Model (13) can be written as

$$
N(x, x) \geq N(x, y), \quad \forall y \in[\underline{x}, \bar{x}],
$$

which means that $N(x, y)$ achieves its maximal value at $y=$ $x$. Thus, $N(x, y)$ satisfies the first-order condition

$$
\left.\frac{\partial N(x, y)}{\partial y}\right|_{y=x}=0
$$

and the second-order condition

$$
\left.\frac{\partial^{2} N(x, y)}{\partial y^{2}}\right|_{y=x}<0
$$

From the first-order condition, we can get

$$
a^{\prime}(x)+\frac{k_{1}^{2}}{c} b(x) b^{\prime}(x)+k_{2} x b^{\prime}(x)=0, \quad \forall x \in[\underline{x}, \bar{x}],
$$

that is,

$$
a^{\prime}(x)+\left(k_{2} x+\frac{k_{1}^{2}}{c} b(x)\right) b^{\prime}(x)=0 .
$$

Equation (14) holds. Following the second-order condition, we have

$$
a^{\prime \prime}(x)+\frac{k_{1}^{2}}{c}\left(b^{\prime}(x)\right)^{2}+\frac{k_{1}^{2}}{c} b(x) b^{\prime \prime}(x)+k_{2} x b^{\prime \prime}(x)<0 .
$$

Differentiating (19) with respect to $x$ yields

$$
\begin{gathered}
a^{\prime \prime}(x)+\frac{k_{1}^{2}}{c}\left(b^{\prime}(x)\right)^{2}+\frac{k_{1}^{2}}{c} b(x) b^{\prime \prime}(x) \\
+k_{2} b^{\prime}(x)+k_{2} x b^{\prime \prime}(x)=0 .
\end{gathered}
$$

It follows from (21), (22), and $k_{2}>0$ that

$$
b^{\prime}(x)>0 \text {. }
$$

Equation (15) holds.

On the other hand, by integrating (14) and taking note of $b^{\prime}(x)>0$, when $x>y$, we can get

$$
\begin{aligned}
a(x)-a(y) & =-\int_{y}^{x}\left(k_{2} s+\frac{k_{1}^{2}}{c} b(s)\right) b^{\prime}(s) d s \\
& \geq-\int_{y}^{x}\left(k_{2} x+\frac{k_{1}^{2}}{c} b(s)\right) b^{\prime}(s) d s \\
& =-\left.\left(k_{2} x b(s)+\frac{k_{1}^{2}}{2 c} b^{2}(s)\right)\right|_{y} ^{x} \\
& =-\left(k_{2} x b(x)+\frac{k_{1}^{2}}{2 c} b^{2}(x)\right. \\
& \left.\quad-k_{2} x b(y)-\frac{k_{1}^{2}}{2 c} b^{2}(y)\right) ;
\end{aligned}
$$

hence,

$$
a(x)+\frac{k_{1}^{2}}{2 c} b^{2}(x)+k_{2} x b(x) \geq a(y)+\frac{k_{1}^{2}}{2 c} b^{2}(y)+k_{2} x b(y) ;
$$

that is, the incentive compatible constraint in Model (13) is satisfied when $x>y$.

Similarly, the above inequality holds when $x<y$. Therefore, the incentive compatible constraint in Model (13) is satisfied for any $x, y \in[\underline{x}, \bar{x}]$. The proof of this proposition is complete.

Remark 8. If the ability of the employee is higher, the bonus coefficient of the wage is also higher; that is, the bonus coefficient of the wage is increasing with the ability of the employee.

Proposition 9. The participation constraint in Model (13) is equivalent to

$$
a(\underline{x})+\frac{k_{1}^{2}}{2 c} b^{2}(\underline{x})+k_{2} \underline{x} b(\underline{x})=u_{0} .
$$


Proof. Let $u(x)=a(x)+\left(k_{1}^{2} / 2 c\right) b^{2}(x)+k_{2} x b(x)$ be the income of the employee under her optimal effort level. Combining with (14), we have

$$
\begin{aligned}
u^{\prime}(x) & =a^{\prime}(x)+\frac{k_{1}^{2}}{c} b(x) b^{\prime}(x)+k_{2} b(x)+k_{2} x b^{\prime}(x) \\
& =k_{2} b(x)>0 ;
\end{aligned}
$$

that is, the income of the employee is increasing with his ability; therefore, for any $x \in[\underline{x}, \bar{x}]$, there exists

$$
\begin{aligned}
a(x) & +\frac{k_{1}^{2}}{2 c} b^{2}(x)+k_{2} x b(x) \\
& \geq a(\underline{x})+\frac{k_{1}^{2}}{2 c} b^{2}(\underline{x})+k_{2} \underline{x} b(\underline{x}) \geq u_{0} .
\end{aligned}
$$

As a matter of fact, the inequality $a(\underline{x})+\left(k_{1}^{2} / 2 c\right) b^{2}(\underline{x})+$ $k_{2} \underline{x} b(\underline{x}) \geq u_{0}$ is binding under the optimal wage contract. Because otherwise one can design a new wage mechanism $\left(a^{*}(x), b(x)\right)$ such that

$$
\begin{gathered}
a^{*}(\underline{x})+\frac{k_{1}^{2}}{2 c} b^{2}(\underline{x})+k_{2} \underline{x} b(\underline{x})=u_{0}, \\
\frac{d a^{*}(x)}{d x}=\frac{d a(x)}{d x} .
\end{gathered}
$$

It is easy to prove that $\left(a^{*}(x), b(x)\right)$ is also feasible for Model (13) and $a^{*}(x) \leq a(x)$ for all $x \in[\underline{x}, \bar{x}]$. However, under this new wage mechanism, the employer will obtain more profit; thus, the constraint $a(\underline{x})+\left(k_{1}^{2} / 2 c\right) b^{2}(\underline{x})+k_{2} \underline{x} b(\underline{x}) \geq$ $u_{0}$ is binding under the optimal wage contract. The proof is complete.

Proposition 10. The objective function of Model (13) can be written as

$$
\begin{gathered}
E\left[\frac{k_{1}^{2}}{c} b(\xi)+k_{2} \xi-a(\xi)-\frac{k_{1}^{2}}{c} b^{2}(\xi)-k_{2} \xi b(\xi)\right] \\
=\int_{\underline{x}}^{\bar{x}}\left(\frac{k_{1}^{2}}{c} b(x)+k_{2} x-u_{0}-\frac{k_{1}^{2}}{2 c} b^{2}(x)\right. \\
\left.-\frac{1-\Phi(x)}{\phi(x)} k_{2} b(x)\right) \phi(x) d x .
\end{gathered}
$$

Proof. By (27) and $u(\underline{x})=u_{0}$, we can obtain

$$
u(x)=k_{2} \int_{\underline{x}}^{x} b(s) d s+u_{0} .
$$

It follows from the definition of $u(x)$ in the proof of Proposition 9 that

$$
a(x)=k_{2} \int_{\underline{x}}^{x} b(s) d s+u_{0}-\frac{k_{1}^{2}}{2 c} b^{2}(x)-k_{2} x b(x) .
$$

Substituting (32) into the objective function of Model (13) yields

$$
E\left[\frac{k_{1}^{2}}{c} b(\xi)+k_{2} \xi-k_{2} \int_{\underline{x}}^{\xi} b(s) d s-u_{0}-\frac{k_{1}^{2}}{2 c} b^{2}(\xi)\right] .
$$

Denote $v(x)=\left(k_{1}^{2} / c\right) b(x)+k_{2} x-k_{2} \int_{x}^{x} b(s) d s-u_{0}-$ $\left(k_{1}^{2} / 2 c\right) b^{2}(x)$ as the profit function of the employer; we can get

$$
v^{\prime}(x)=\frac{k_{1}^{2}}{c}(1-b(x)) b^{\prime}(x)+k_{2}(1-b(x)) .
$$

Noting that $b^{\prime}(x)>0,0 \leq b(x) \leq 1$, we can obtain $v^{\prime}(x) \geq 0$; that is, $v(x)$ is increasing with respect to $x$. By Lemma 5 , the objective function of Model (13) can be written as

$$
\begin{gathered}
E\left[\frac{k_{1}^{2}}{c} b(\xi)+k_{2} \xi-k_{2} \int_{\underline{x}}^{\xi} b(s) d s-u_{0}-\frac{k_{1}^{2}}{2 c} b^{2}(\xi)\right] \\
=\int_{\underline{x}}^{\bar{x}}\left(\frac{k_{1}^{2}}{c} b(x)+k_{2} x-k_{2} \int_{\underline{x}}^{x} b(s) d s-u_{0}\right. \\
\left.\quad-\frac{k_{1}^{2}}{2 c} b^{2}(x)\right) d \Phi(x) \\
=\int_{\underline{x}}^{\bar{x}}\left(\frac{k_{1}^{2}}{c} b(x)+k_{2} x-u_{0}-\frac{k_{1}^{2}}{2 c} b^{2}(x)\right. \\
\left.\quad-\frac{1-\Phi(x)}{\phi(x)} k_{2} b(x)\right) \phi(x) d x .
\end{gathered}
$$

Therefore, the proof of this proposition is complete.

Above all, the crisp equivalent form of Model (13) can be expressed as follows.

Proposition 11. Model (13) is equivalent to

$$
\begin{array}{r}
\max _{b(\cdot)} \quad \int_{\underline{x}}^{\bar{x}}\left(\frac{k_{1}^{2}}{c} b(x)+k_{2} x-u_{0}-\frac{k_{1}^{2}}{2 c} b^{2}(x)\right. \\
\left.-\frac{1-\Phi(x)}{\phi(x)} k_{2} b(x)\right) \phi(x) d x
\end{array}
$$

subject to: $\quad \mathrm{b}^{\prime}(\mathrm{x})>0, \quad \forall \mathrm{x} \in[\underline{\mathrm{x}}, \overline{\mathrm{x}}]$.

Proof. It can be easily obtained according to Propositions 610.

4.2. Optimal Solution. The optimal solution of the uncertain wage contract model is given in this subsection.

Proposition 12. The optimal solution $b^{*}(x)$ for Model (36) satisfies

$$
b^{*}(x)=1-\frac{c k_{2}(1-\Phi(x))}{k_{1}^{2} \phi(x)} .
$$

Proof. The second-order variation of the objective function of Model (36) with respect to $b(x)$ is as follows:

$$
\delta^{2} E[v(\xi)]=\int_{\underline{x}}^{\bar{x}}\left(-\frac{k_{1}^{2}}{c}\right) \phi(x)(\delta b(x))^{2} d x .
$$


It is easy to see that $\delta^{2} E[v(\xi)]<0$; the optimal bonus coefficient $b^{*}(x)$ satisfies the first-order condition

$$
\begin{aligned}
\delta E[v(\xi)]=\int_{\underline{x}}^{\bar{x}} & \left(\frac{k_{1}^{2}}{c}-\frac{k_{1}^{2}}{c} b^{*}(x)-\frac{k_{2}(1-\Phi(x))}{\phi(x)}\right) \\
& \times \phi(x) \delta b(x) d x=0 ;
\end{aligned}
$$

that is,

$$
\frac{k_{1}^{2}}{c}-\frac{k_{1}^{2}}{c} b^{*}(x)-\frac{k_{2}(1-\Phi(x))}{\phi(x)}=0 ;
$$

thus,

$$
b^{*}(x)=1-\frac{c k_{2}(1-\Phi(x))}{k_{1}^{2} \phi(x)} .
$$

In the following, we testify that $d b^{*}(x) / d x>0$. Since $(d / d x)((1-\Phi(x)) / \phi(x))<0$,

$$
\frac{d b^{*}(x)}{d x}=-\frac{c k_{2}}{k_{1}^{2}} \frac{d}{d x}\left(\frac{1-\Phi(x)}{\phi(x)}\right)>0 .
$$

The proof is complete.

Corollary 13. The optimal effort of the employee, the fixed wage, and the total wage paid by the employer are as follows:

$$
\begin{gathered}
e^{*}(x)=\frac{k_{1}}{c}\left(1-\frac{c k_{2}(1-\Phi(x))}{k_{1}^{2} \phi(x)}\right), \\
a^{*}(x)=k_{2} \int_{\underline{x}}^{x}\left(1-\frac{c k_{2}(1-\Phi(s))}{k_{1}^{2} \phi(s)}\right) d s \\
+u_{0}-\frac{k_{1}^{2}}{2 c}\left(1-\frac{c k_{2}(1-\Phi(x))}{k_{1}^{2} \phi(x)}\right)^{2} \\
-k_{2} x\left(1-\frac{c k_{2}(1-\Phi(x))}{k_{1}^{2} \phi(x)}\right), \\
\left.w^{*}(x)=\frac{k_{1}^{2}}{2 c}\left(1-\frac{c k_{2}(1-\Phi(x))}{k_{1}^{2} \phi(x)}\right)^{2}\right) d s+u_{0} . \\
+k_{2} \int_{\underline{x}}^{x}\left(1-\frac{c k_{2}(1-\Phi(s))}{k_{1}^{2} \phi(s)}\right)
\end{gathered}
$$

Proof. It can be easily obtained from (10), (32), and the definition of the wage.

From the optimal solution $\left(e^{*}(x), a^{*}(x), b^{*}(x)\right)$ of Model (9), it is easy to see that the fixed wage is increasing with the employee's reservation utility while the employee's effort level and the bonus coefficient is independent of it.

Proposition 14. The optimal effort level $e^{*}(x)$ of the employee, the fixed wage $a^{*}(x)$, and the optimal wage $w^{*}(x)$ satisfy the following:

(i) $e^{*}(x)$ is increasing in $x$; (ii) $a^{*}(x)$ is decreasing in $x$;

(iii) $w^{*}(x)$ is increasing in $x$.

Proof. Result (i) can be immediately obtained from (10) and (15). Results (ii) and (iii) are proved as follows.

It follows from (32) that

$$
a^{*}(x)=k_{2} \int_{\underline{x}}^{x} b^{*}(s) d s+u_{0}-\frac{k_{1}^{2}}{2 c}\left(b^{*}(x)\right)^{2}-k_{2} x b^{*}(x) \text {. }
$$

Differentiating (46) and noting $b^{*}(x) \geq 0, d b^{*}(x) / d x>0$, we can get

$$
\frac{d a^{*}(x)}{d x}=-\frac{k_{1}^{2} b^{*}(x)}{c} \frac{d b^{*}(x)}{d x}-k_{2} x \frac{d b^{*}(x)}{d x}<0 ;
$$

that is, $a^{*}(x)$ is decreasing in $x$. Result (ii) holds.

It follows from (45) that

$$
\frac{d w^{*}(x)}{d x}=\frac{k_{1}^{2} b^{*}(x)}{c} \frac{d b^{*}(x)}{d x}+k_{2} b^{*}(x) .
$$

Noting that $b^{*}(x) \geq 0$ and $d b^{*}(x) / d x>0$, we can get

$$
\frac{d w^{*}(x)}{d x} \geq 0
$$

that is, $w^{*}(x)$ is increasing in $x$. Result (iii) holds. The proof is complete.

This proposition shows that the fixed wage $a^{*}(x)$ is decreasing with the ability of the employee while the total wage $w^{*}(x)$ is increasing with the ability of the employee. Because the employee has private information about her ability; however, such a wage scheme would induce the employee to understate her ability in an attempt to receive higher fixed wage. To ensure that the employee does not misreport her ability, the employee must be provided with informational rents. Furthermore, to deter higher ability employees from mimicking as lower ones, higher ability employees must earn larger rents than lower ones.

\section{Numerical Example}

In this section, a numerical example is given to verify the validity of the proposed model. 


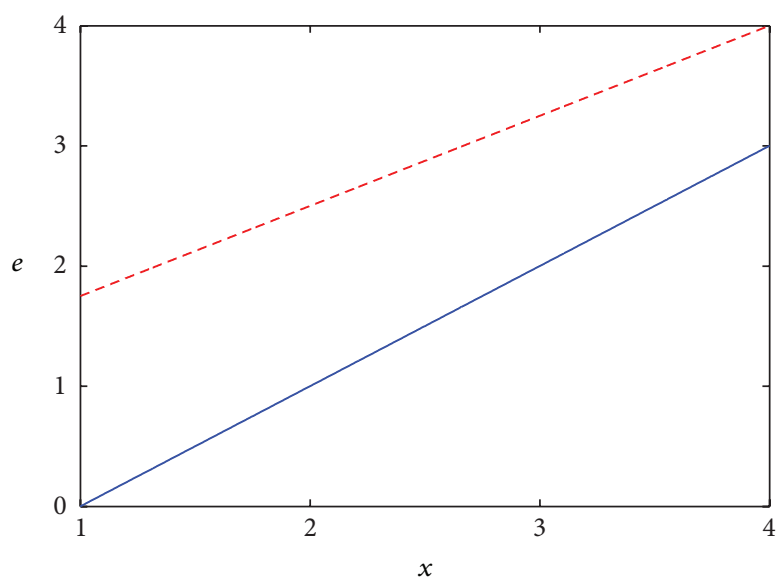

$$
\begin{aligned}
-k_{1} & =3 \\
--- & k_{1}=4
\end{aligned}
$$

(a) Optimal effort level with different $k_{1}$

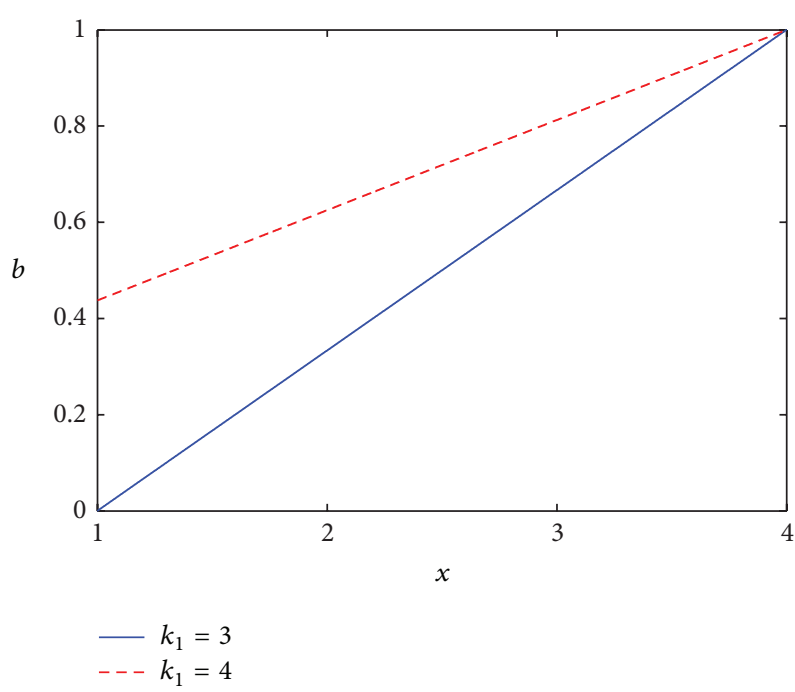

(c) Optimal bonus coefficient with different $k_{1}$

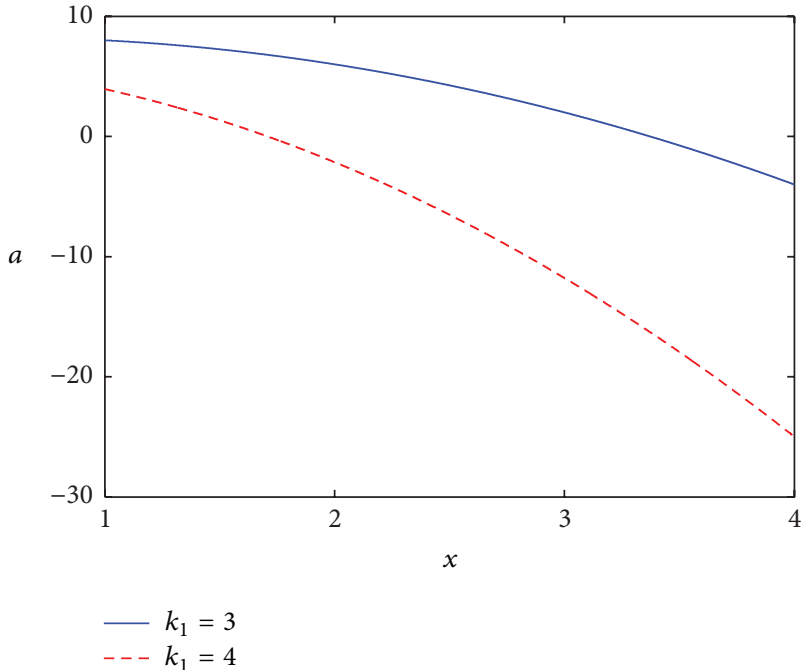

(b) Optimal fixed wage with different $k_{1}$

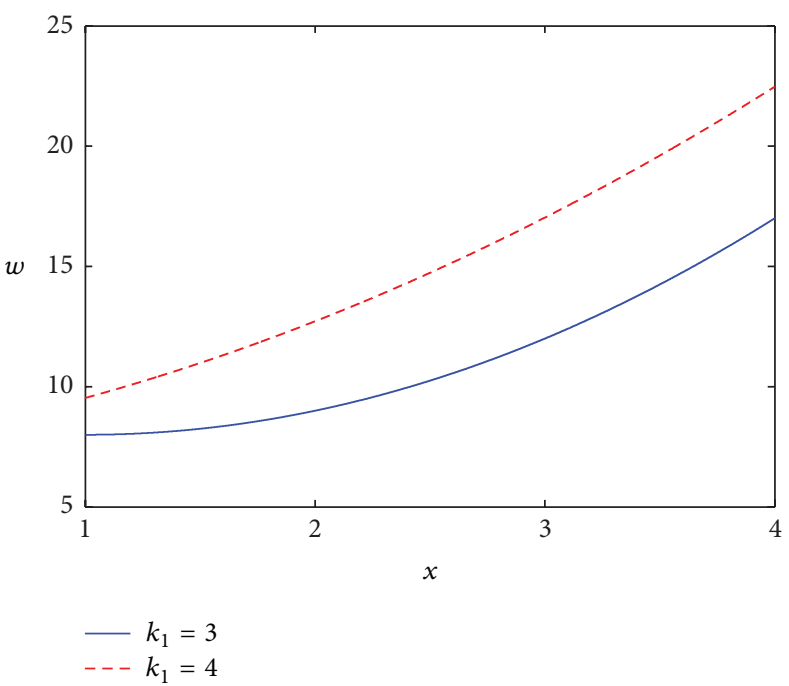

(d) Optimal wage with different $k_{1}$

Figure 1: Optimal contract with different parameter $k_{1}$.

Let $k_{1}=k_{2}=3, c=1$, and $u_{0}=8$, and $\xi$ is a linear uncertain variable; the support set of it is in $[1,4]$. The uncertain wage contract model can be written as

$$
\max _{e(\cdot), a(\cdot), b(\cdot)} E[3 e(\xi)+3 \xi-a(\xi)-b(\xi)(3 e(\xi)+3 \xi)]
$$

subject to : $\quad e^{*}(x) \in \arg \max _{e(\cdot)}(a(x)+b(x)(3 e(x)+3 x)$

$$
\left.-\frac{1}{2} e^{2}(x)\right), \quad \forall x \in[1,4]
$$

$$
\begin{array}{r}
a(x)+b(x)(3 e(x)+3 x)-\frac{1}{2}(e(x))^{2} \\
\geq a(y)+b(y)(3 e(y)+3 x)-\frac{1}{2}(e(y))^{2}, \\
\forall x, y \in[1,4]
\end{array}
$$

$$
\begin{array}{r}
a(x)+b(x)(3 e(x)+3 x)-\frac{1}{2}(e(x))^{2} \geq 8, \\
\forall x \in[1,4] .
\end{array}
$$

By Propositions 6-12, the optimal effort of employee and the optimal wage contract can be calculated as follows:

$$
\begin{array}{cc}
e^{*}(x)=x-1, & a^{*}(x)=-x^{2}+x+8, \\
b^{*}(x)=\frac{1}{3} x-\frac{1}{3}, & w^{*}(x)=x^{2}-2 x+9 .
\end{array}
$$

The profit function of the employer is

$$
V(q, x)=-x^{2}+8 x-12 .
$$

The expected profit of the employer is

$$
E V(q, \xi)=1 \text {. }
$$




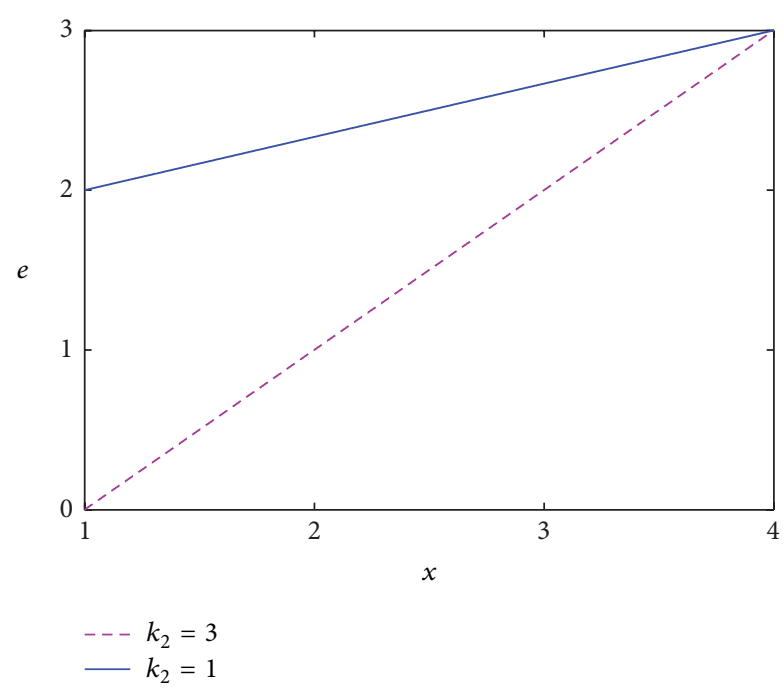

(a) Optimal effort level with different $k_{2}$

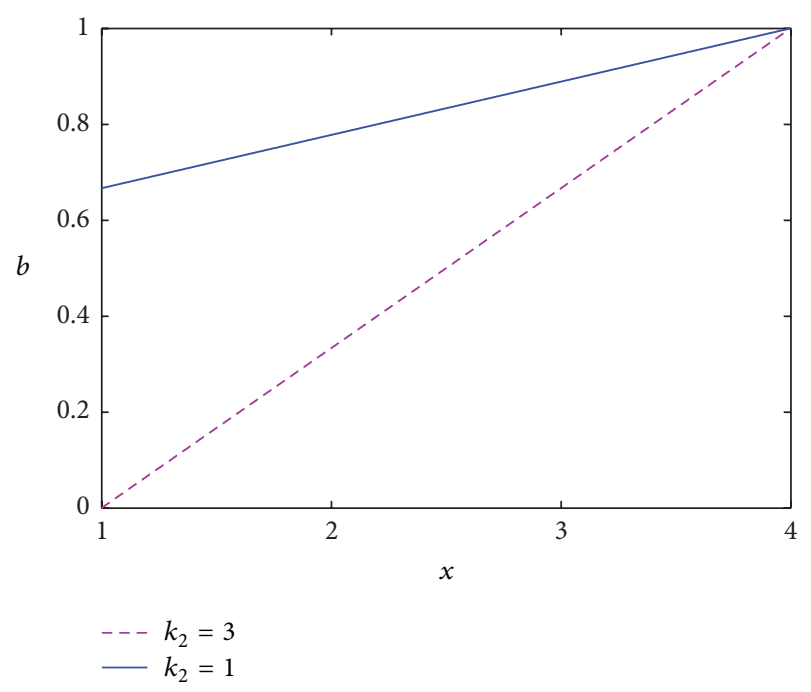

(c) Optimal bonus coefficient with different $k_{2}$

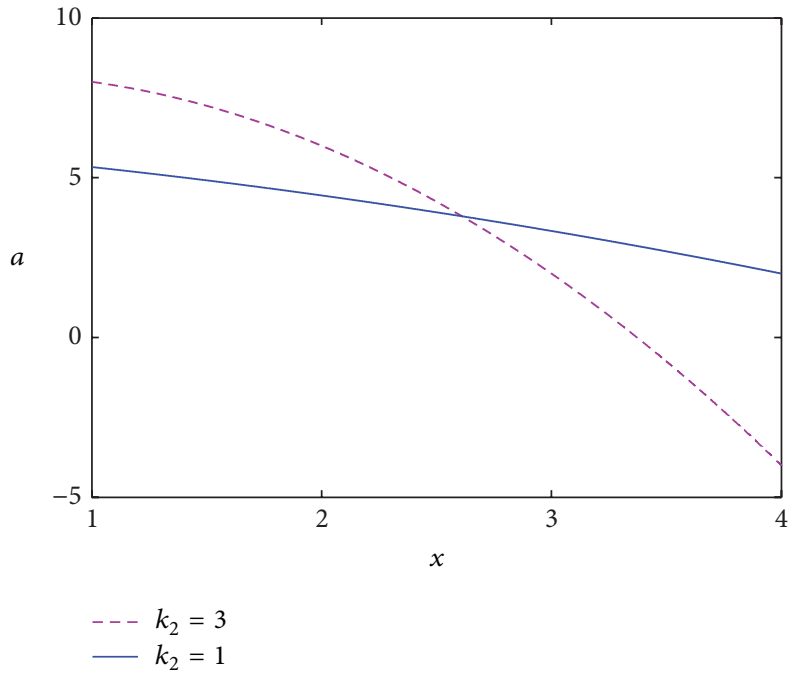

(b) Optimal fixed wage with different $k_{2}$

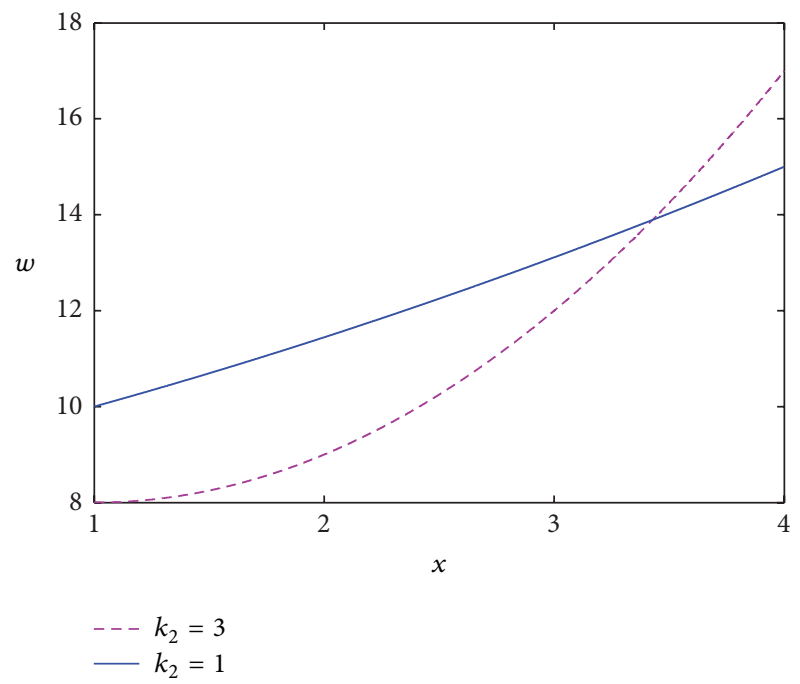

(d) Optimal wage with different $k_{2}$

FIGURE 2: Optimal contract with different parameter $k_{2}$.

The net income of the employee is

$$
U(w, e)=\frac{1}{2} x^{2}-x+\frac{17}{2} .
$$

Figures 1 and 2 give the optimal effort $e^{*}(x)$ of the employee, the optimal wage contract $\left(a^{*}(x), b^{*}(x)\right)$, and the optimal wage $w^{*}(x)$ with different parameter $k_{1}$ and $k_{2}$.

Figure 1 indicates that with the increase of the employee's ability, the employee's effort level increases, the fixed wage decreases, and the bonus coefficient and the wage paid by the employer increase. Furthermore, if parameter $k_{1}$ becomes larger, that is, the contribution of the employee's effort level to the productivity becomes greater, the employee pays more effort, the fixed wage becomes lower, and the bonus coefficient and the wage get higher.

Figure 2 shows that the optimal contract has the same monotonicity with Figure 1. In addition, Figure 2 also shows that if the parameter $k_{2}$ becomes larger, that is, the contribution of the employee's ability to the productivity becomes greater, the optimal effort level and the optimal bonus coefficient become smaller, and there exists a threshold for ability in which the fixed wage becomes higher when the ability of the employee is below it, and when the ability of the employee exceeds it the fixed wage becomes lower; in this case, the purpose of the employer is to motivate the employee to devote more efforts. Accordingly, with the increase of parameter $k_{2}$, there exists another threshold below which the total wage is lower; when the ability of the employee exceeds it, the total wage is higher; this ensures that the employee with higher ability gets higher wages.

\section{Conclusion}

This paper presents an uncertain wage contract model under adverse selection and hazard moral, in which the ability of 
the employee is unknown to the employer and is denoted by an uncertain variable, the effort level of the employee is unobservable to the employer, and the employee can select an effort level to maximize her utility. The purpose of the model is to maximize the employer's profit. To obtain the optimal solution, the equivalent model of the uncertain wage contract model is proposed. Applying the variational method, we get the optimal solution. In the end, a numerical example is given to verify the effectiveness of the established model. The result shows that the employer's effort and the wage are increasing with the employee's ability.

\section{Conflict of Interests}

The authors declare that there is no conflict of interests regarding the publication of this paper.

\section{Acknowledgments}

This work was supported partially by the Natural Science Foundation of China under Grants no. 71271151, 71371133, 71071106, and 71301114 and the Research Fund for the Specialized Research Fund for the Doctoral Program of Higher Education under Grants no. 20120032110071 and 20130032110015.

\section{References}

[1] R. B. Myerson, "Optimal coordination mechanisms in generalized principal-agent problems," Journal of Mathematical Economics, vol. 10, no. 1, pp. 67-81, 1982.

[2] S. J. Grossman and O. D. Hart, "An analysis of the principalagent problem," Econometrica, vol. 51, no. 1, pp. 7-45, 1983.

[3] F. H. Page, Jr., "Optimal contract mechanisms for principalagent problems with moral hazard and adverse selection," Economic Theory, vol. 1, no. 4, pp. 323-338, 1991.

[4] Ö. Özer and G. Raz, "Supply chain sourcing under asymmetric information," Production and Operations Management, vol. 20, no. 1, pp. 92-115, 2011.

[5] Y. Lan, R. Zhao, and W. Tang, "A yardstick competition approach to a multi-firm regulation problem under asymmetric information," Journal of Computational and Applied Mathematics, vol. 249, pp. 24-36, 2013.

[6] B. C. Greenwald, "Adverse selection in labour market," The Review of Economic Studies, vol. 53, no. 3, pp. 325-347, 1986.

[7] F. Chen, "Salesforce incentives, market information, and production/inventory planning," Management Science, vol. 51, no. 1, pp. 60-75, 2005.

[8] B. Liu, "Why is there a need for uncertainty theory?" Journal of Uncertain Systems, vol. 6, no. 1, pp. 3-10, 2012.

[9] B. Liu, Uncertainty Theory, vol. 154 of Studies in Fuzziness and Soft Computing, Springer, Berlin, Germany, 2nd edition, 2007.

[10] Y. Zhu, "Uncertain optimal control with application to a portfolio selection model," Cybernetics and Systems, vol. 41, no. 7, pp. 535-547, 2010.

[11] X. Chen and B. Liu, "Existence and uniqueness theorem for uncertain differential equations," Fuzzy Optimization and Decision Making, vol. 9, no. 1, pp. 69-81, 2010.

[12] B. Liu, Theory and Practice of Uncertain Programming, Springer, Berlin, Germany, 2nd edition, 2009.
[13] Y.-F. Lan, Y.-K. Liu, and G.-J. Sun, "Modeling fuzzy multiperiod production planning and sourcing problem with credibility service levels," Journal of Computational and Applied Mathematics, vol. 231, no. 1, pp. 208-221, 2009.

[14] Y. Lan, R. Zhao, and W. Tang, "Minimum risk criterion for uncertain production planning problems," Computers and Industrial Engineering, vol. 61, no. 3, pp. 591-599, 2011.

[15] R. Qin, Y.-K. Liu, and Z.-Q. Liu, "Methods of critical value reduction for type-2 fuzzy variables and their applications," Journal of Computational and Applied Mathematics, vol. 235, no. 5, pp. 1454-1481, 2011.

[16] Y. Liu, X. Wu, and F. Hao, "A new Chance-Variance optimization criterion for portfolio selection in uncertain decision systems," Expert Systems with Applications, vol. 39, no. 7, pp. 6514-6526, 2012.

[17] L. Cui, R. Zhao, and W. Tang, "Principal-agent problem in a fuzzy environment," IEEE Transactions on Fuzzy Systems, vol. 15, no. 6, pp. 1230-1237, 2007.

[18] Y. Lan, R. Zhao, and W. Tang, "A bilevel fuzzy principalagent model for optimal nonlinear taxation problems," Fuzzy Optimization and Decision Making, vol. 10, no. 3, pp. 211-232, 2011.

[19] Y. Lan, R. Zhao, and W. Tang, "A fuzzy supply chain contract problem with pricing and warranty," Journal of Intelligent and Fuzzy Systems, vol. 26, no. 3, pp. 1527-1538, 2014.

[20] B. Liu, Uncertainty Theory: A Branch of Mathematics for Modeling Human Uncertainty, Springer, Berlin, Germany, 2011.

[21] B. Liu, Uncertainty Theory, 4th edition, 2012, http://www.orsc .edu.cn/ liu/ut.pdf.

[22] G. Wang, W. Tang, and R. Zhao, "An uncertain price discrimination model in labor market," Soft Computing, vol. 17, no. 4, pp. 579-585, 2012.

[23] R. Mu, Y. Lan, and W. Tang, "An uncertain contract model for rural migrant worker's employment problems," Fuzzy Optimization and Decision Making, vol. 12, no. 1, pp. 29-39, 2013.

[24] B. Liu, "Some research problems in uncertainty theory," Journal of Uncertain Systems, vol. 3, no. 1, pp. 3-10, 2009.

[25] Y. Liu and M. Ha, "Expected value of function of uncertain variables," Journal of Uncertain Systems, vol. 4, no. 3, pp. 181-186, 2010.

[26] S. Dutta, "Managerial expertise, private information, and payperformance sensitivity," Management Science, vol. 54, no. 3, pp. 429-442, 2008.

[27] E. Siemsen, S. Balasubramanian, and A. V. Roth, "Incentives that induce task-related effort, helping, and knowledge sharing in workgroups," Management Science, vol. 53, no. 10, pp. 15331550, 2007.

[28] R. B. Myerson, "Incentive compatibility and the bargaining problem," Econometrica, vol. 47, no. 1, pp. 61-73, 1979. 


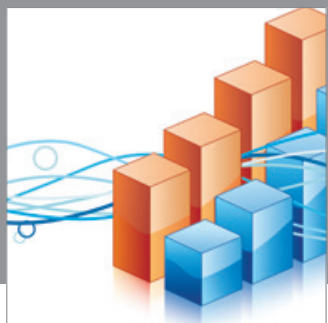

Advances in

Operations Research

mansans

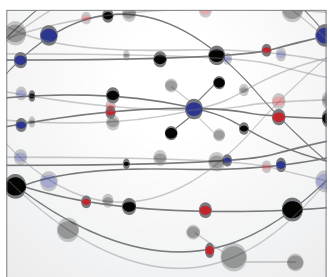

The Scientific World Journal
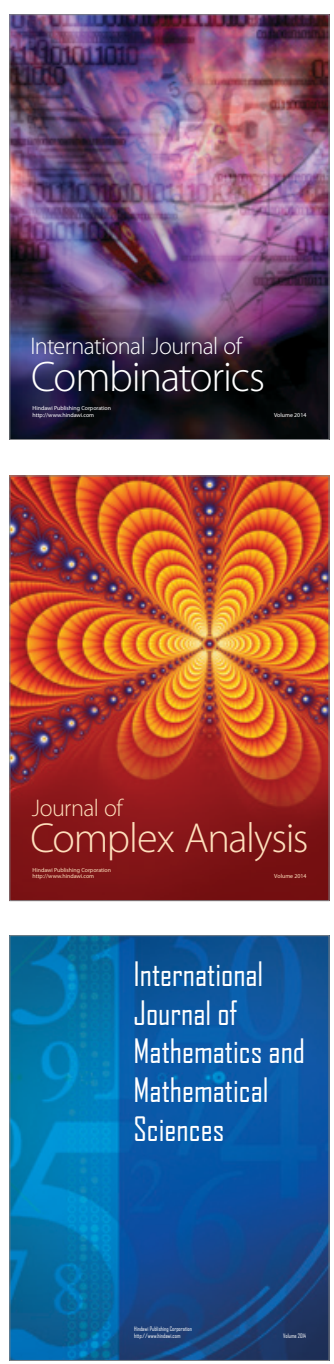
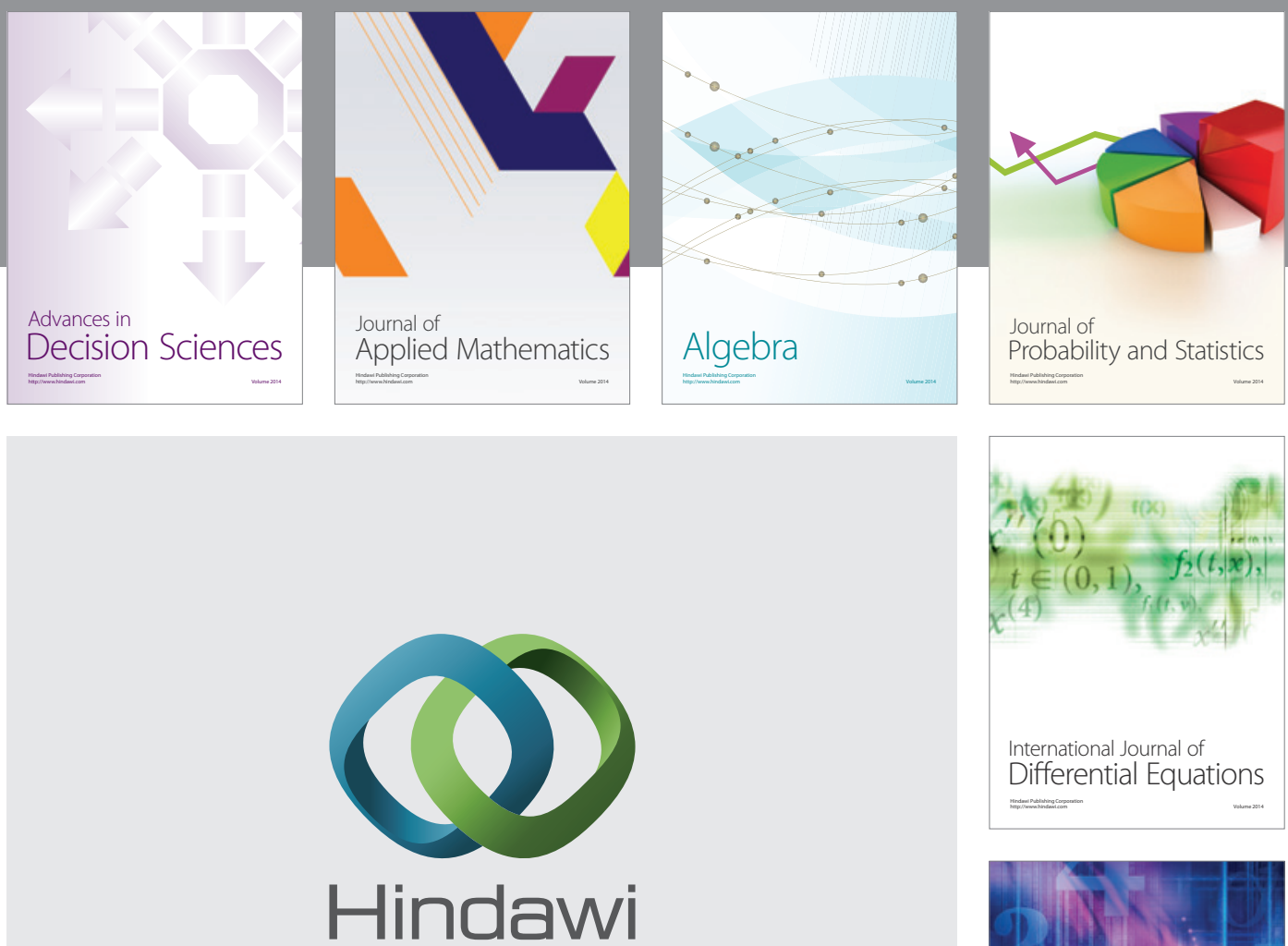

Submit your manuscripts at http://www.hindawi.com
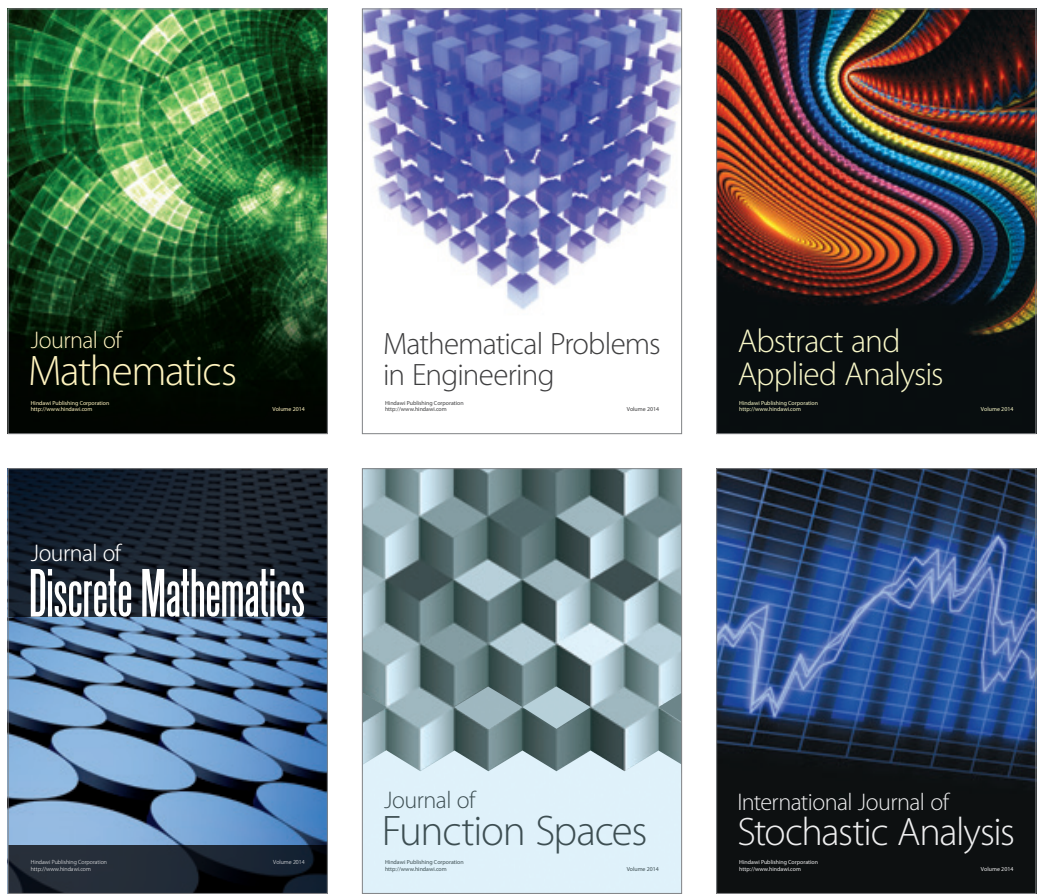

Journal of

Function Spaces

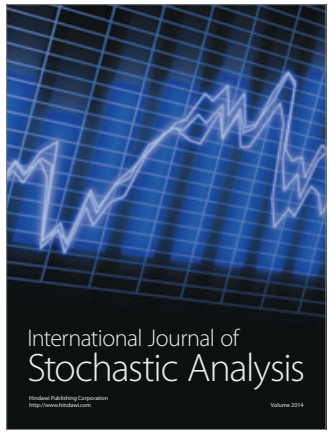

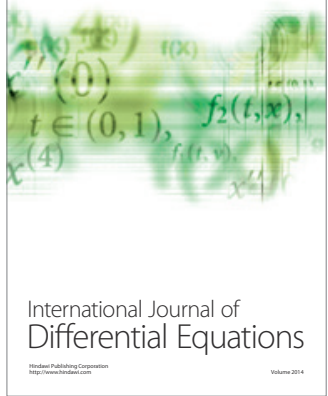
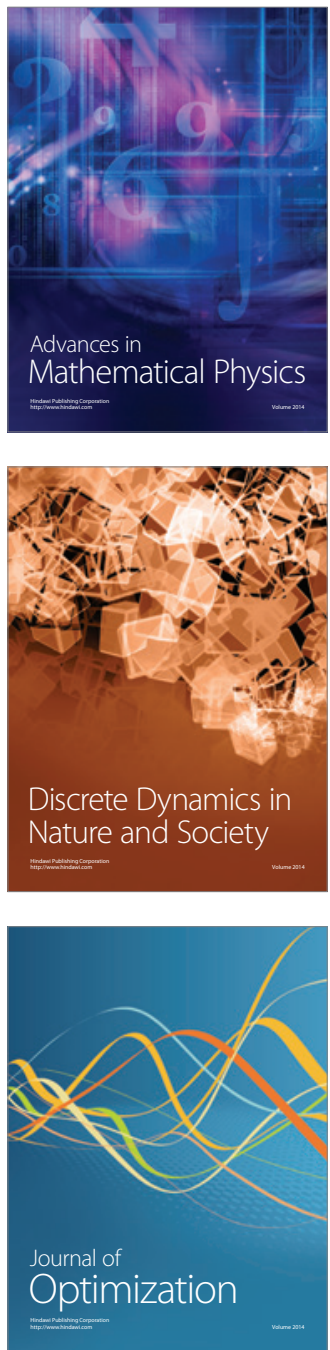